\title{
CORRIGENDUM
}

\section{Shifts in reinforcement signalling while playing slot-machines as a function of prior experience and impulsivity}

\author{
R Shao, J Read, TEJ Behrens and RD Rogers
}

Translational Psychiatry (2013) 3, e235; doi:10.1038/tp.2013.10; published online 26 February 2013

Correction to: Translational Psychiatry (2013) 3, e213; 10.1038/tp.2012.134; published online 15 January 2013

In the second sentence of the Introduction, the time period for the stated slot-machine income in Ontario was incorrect.
The income of $\sim \$ 3135660000$ was generated for the period 2002-2003, not the year 2004. 